\title{
Business not as usual: how multisectoral collaboration can promote transformative change for health and sustainable development
}

\author{
Shyama Kuruvilla and colleagues present findings across 12 country case studies of \\ multisectoral collaboration, showing how diverse sectors intentionally shape new ways of \\ collaborating and learning, using "business not as usual" strategies to transform situations and \\ achieve shared goals
}

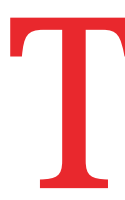

he 2030 Agenda for Sustainable Development states that if the "interlinkages and integrated nature of the Sustainable Development Goals (SDGs)” are

\section{REY MESSAGES}

- We present a model of enabling factors for effective multisectoral collaboration for improvements in health and sustainable development:

- Drive change: assess whether desired change is better off achieved by multisectoral collaboration; drive forward collaboration by mobilising a critical mass of policy and public attention

- Define: frame the problem strategically and holistically so that all sectors and stakeholders can see the benefits of collaboration and contribution to the public good

- Design: create solutions relevant to context, building on existing mechanisms, and leverage the strengths of diverse sectors for collective impact

- Relate: ensure resources for multisectoral collaboration mechanisms, including for open communication and deliberation on evidence, norms, and innovation across all components of collaboration

- Realise: learn by doing, and adapt with regular feedback. Remain open to redefining and redesigning the collaboration to ensure relevance, effectiveness, and responsiveness to change

- Capture success: agree on success markers, using qualitative and quantitative methods to monitor results regularly and comprehensively, and learn from both failures and successes to inform action and sustain gains. realised, then "the lives of all will be profoundly improved and our world will be transformed for the better." ${ }^{1}$

In line with the SDGs, multisectoral action (box 1) is a key action area of the Global Strategy for Women's, Children's and Adolescents' Health. ${ }^{2}$ It is central to other global health priorities, for example, universal health coverage, the prevention and control of non-communicable diseases, and the "health in all policies" approach. A fundamental question arises: could the transformative changes envisioned in the SDGs be achieved by each sector acting independently, or do they require multisectoral collaboration (see box 1 for definitions)?

To achieve the SDGs, it is vital to know when multisectoral collaboration will be most effective, how to ensure efficiency, and what factors enable these collaborations to contribute to transformative change-to "business not as usual."

The series on success factors for women's and children's health and other studies found that during the years of the millennium development goals (20002015), sectors beyond health contributed

\section{Box 1: Definitions}

Stakeholders are actors, whether individuals or groups, who can influence or be affected by a particular concern, process, or outcome. ${ }^{6}$ Stakeholders may include governments, nongovernmental organisations (NGOs), civil society, private actors, international organisations, donors, service users, service providers, the media, and other groups.

Sectors comprise an array of actors and institutions linked by their formal, functional roles or area of work. Highlighted here are sectors related to specific policy areas or topics, including those relevant to the 17 SDGs. These sectors can be supported by institutions, which assume cross cutting functions, such as those responsible for budgeting or planning. These sectors and cross cutting institutions can include both public and private entities. The term "sector" also can be used to denote these entities, as in discussions about the "public sector" and the "private sector."

Multisectoralaction ${ }^{89}$ can occur in three ways:

- Independent action: individual sectors independently undertaking their core business and advancing their own sectors' goals; in so doing they can also contribute to other sectors' goals. For example, health sector investments in children's health could also improve educational performance, and better health and education could contribute to higher productivity and wages in adulthood.

- Intentional collaboration: multiple sectors and stakeholders intentionally coming together and collaborating in a managed process to achieve shared outcomes. This is referred to in this paper as multisectoral collaboration. In the context of the SDGs, shared outcomes of multisectoral collaboration could include joint programmes for poverty reduction, better health and wellbeing, high quality education, improved nutrition, gender equality, economic growth, and other outcomes influencing health and sustainable development.

- Contextual or ecological interactions: there are individual, social, and environmental factors beyond the remit of any sector, that intersect with and influence sectoral work. For example, individuals' biology and behaviours, sociocultural norms, political ideologies, and environmental phenomena. Sectors independently and collaboratively could seek to tackle how these matters influence implementation and impact. 


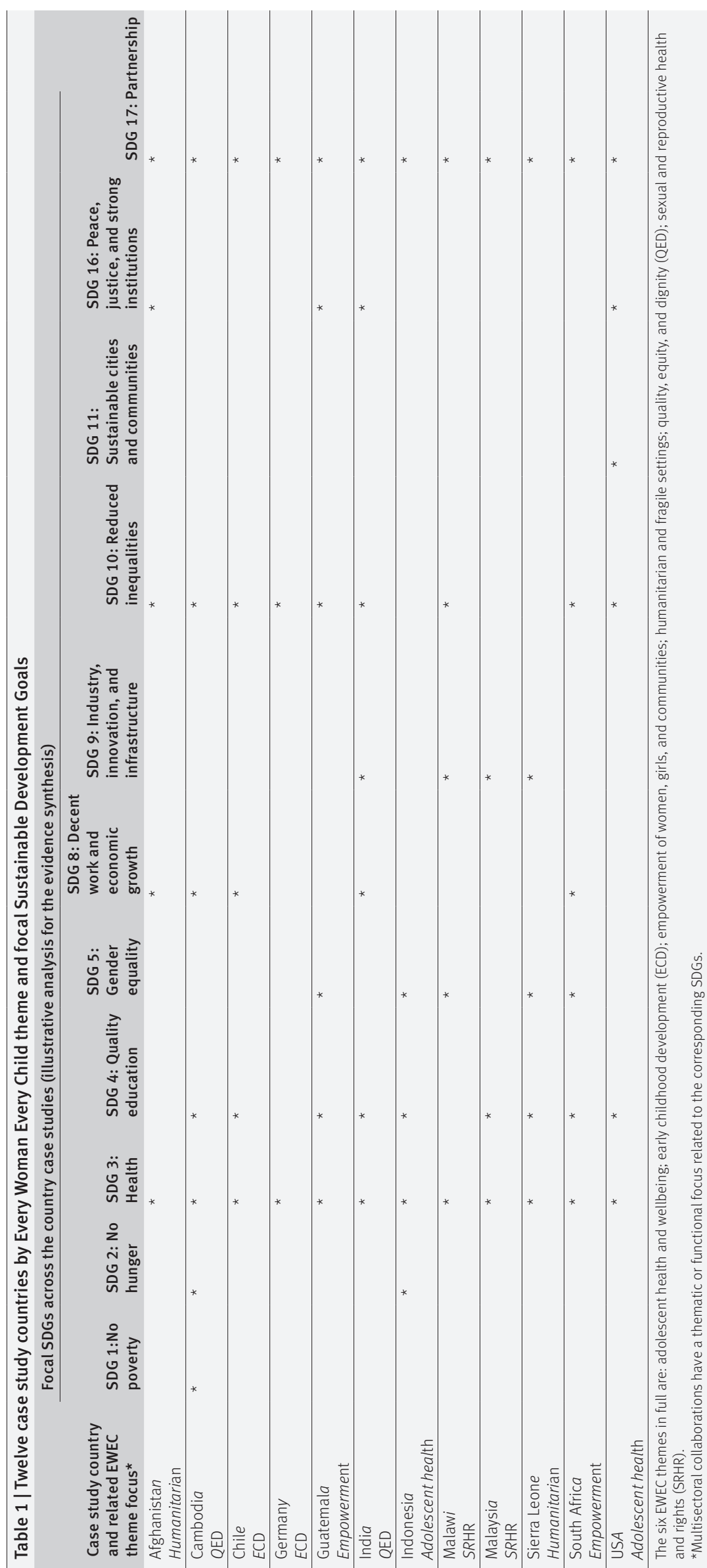

to around $50 \%$ of the reductions in child and maternal mortality achieved in low and middle income countries. ${ }^{10} 11$ This work also showed that some countries' health and development outcomes were improved by health and other sectors acting independently, but in others, improvements were achieved by intentional multisectoral collaboration. ${ }^{10}$

The literature documents how multisectoral collaborations have been planned, implemented, and sustained in various fields of health and in other sectors. ${ }^{8912-14}$ For example, in the field of nutrition, multisectoral collaboration to reduce stunting in children in Peru was achieved when the government required related sectors to work together in "convergence" programming and to align targets and interventions. ${ }^{13}$ With a focus on improving the wellbeing of First Nations people in Canada, a range of multisectoral determinants were considered with respect to community autonomy and governance, different belief systems, social capital, health and social services, and historical, ecological, and life course considerations. ${ }^{12}$

Limited evidence is available about how multisectoral collaborations work specifically to improve women's, children's, and adolescents' health, and about best practices and generalisable principles. ${ }^{14}$ For example, while it is known that policy and context matter for efforts to improve child development and life outcomes, ${ }^{15}$ there is less understanding of the specific entry points and opportunities for involvement by diverse sectors and stakeholders on these matters. ${ }^{1415}$

To contribute to the evidence, the Partnership for Maternal, Newborn, and Child Health (PMNCH) supported the development of 12 country case studies. These were selected from responses to a global call for proposals, using weighted selection criteria.

Each country case study relates to one of six thematic priorities on which PMNCH and other Every Woman Every Child (EWEC) partners agreed to focus on for 2018-2020 to support country implementation of the global strategy. ${ }^{16}$ Since the call for proposals intentionally focused on health and partnership across sectors, all the country case studies related to SDGs 3 and 17; other SDGs were covered based on the context of the multisectoral collaborations (table 1).

The papers in this series show diversity in the selected case studies-in relation to country income level, the type and number of sectors and stakeholders involved, breadth of scope from sub-national or pilot 
programmes to those at scale, and the time span. Some, for example, began as nongovernmental organisation (NGO) led pilots implemented in remote rural areas and were scaled up to national coverage; others were initiated by a president or prime minister and rolled out nationwide over a matter of months. A few were established more recently and for a finite period to accomplish a specific goal; and several are ongoing and open ended, with the longest running since 2002.

We present a synthesis of the country case study findings, and develop a multisectoral collaboration model to inform

\section{How success factors were elucidated}

We anticipated that development of an underlying theoretical basis or model would be helpful in informing action and further development in relation to multisectoral collaboration. ${ }^{17}$ Our model development used a combination of methods, incorporating narrative synthesis ${ }^{17}$ and a multi-grounded theory approach. ${ }^{18}$ This combined approach goes beyond summarising findings to synthesise higher level interpretive findings and systematically develop a theoretical model.

Three main steps were employed to synthesise the country case study findings and develop a multisectoral collaboration model in this paper (supplement 1): conducting preliminary analyses of the country case study findings; synthesising higher level, interpretive findings with reference to a theoretical model; and assessing the robustness of the higher level, interpretative findings and the multisectoral collaboration model.

Conducting preliminary analyses of the country case study findings

The literature review that informed the case study methods guide identified key components of multisectoral collaboration. ${ }^{1419}$ The semi-structured questionnaire in the study series methods guide ${ }^{19}$ provided a template from which to extract, categorise, and analyse the findings from each country case study.

\section{Synthesising higher level, interpretive} findings with reference to a theoretical model A thematic analysis was conducted to synthesise the recurring and prominent themes arising from the preliminary analysis into higher level, interpretive findings. The interpretive findings across the case studies were then analysed with reference to related best practice and a theoretical model. $8912-1419-21$ further policy, action and research.
Best practices in planning, management, research, and other fields tend to follow a common logic, including experiencing a challenge or idea; defining a specific problem or question; developing evidence based solutions and innovations, and deliberating options; implementation and learning; and achieving harmonious resolution. ${ }^{20}$ This logic also seems to hold true for multisectoral collaborations, as evinced in the literature review for this study $^{8912-1419-21}$ and additional references from non-communicable diseases, ${ }^{22}$ early childhood development, ${ }^{15}$ and nutrition. ${ }^{1323}$

This common "logic of inquiry" was elaborated by Dewey in pragmatist philosophy as a systematic way to support societal learning and advancement. ${ }^{20}$ It was applied in a "transactive rationality model" for public policy and administration, ${ }^{21}$ and in other contexts including environmental policy assessment ${ }^{24}$ and strategic crisis management. ${ }^{25}$

In this paper, we used the transactive rationality model ${ }^{21}$ to help synthesise the higher level findings across the country

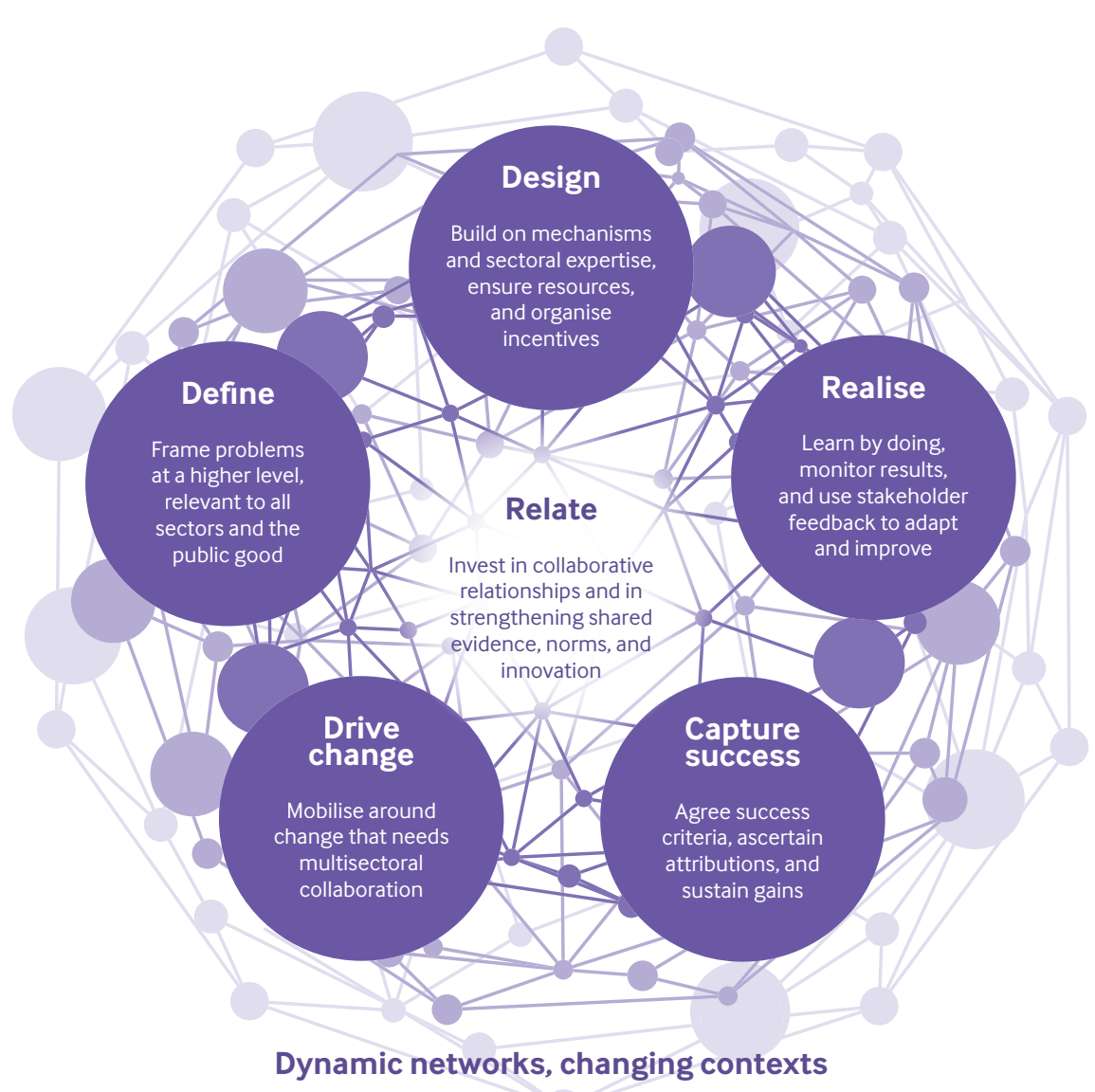

Fig 1 | A multisectoral collaboration model to achieve transformative change. Findings adapted from Dewey $1938^{20}$ and Kuruvilla and Dorstewitz $2010^{21}$ to specify "what makes multisectoral collaborations work"

case studies. We selected this model because it was comparatively assessed as covering all the key components of multisectoral collaboration identified in the literature review and case study methods guide $^{1419}$ (supplement 1), and also as it was explicitly framed as a theoretical "hypothesis" for best practice across a range of contexts. ${ }^{2021}$

To accommodate the specific higher level findings across the country case studies on what works in multisectoral collaboration, we adapted the reference theoretical model (supplement 1, fig 1).

Assessing the robustness of the higher level, interpretative findings and the multisectoral collaboration model.

To accommodate the specific findings on multisectoral collaboration, the reference model was adapted both thematically and graphically (supplement 1, fig 1). This process continued until "theoretical saturation" was reached: that is, when the components of the new multisectoral collaboration model could accommodate all the case study findings without needing further adjustment. ${ }^{17}$ Robustness was also 
assessed by triangulating case study findings from different countries, and by drawing on multidisciplinary perspectives in the literature. The global steering committee and country teams reviewed the model and interpretive findings and confirmed that these reflected their experiences and lessons learnt. Expert peer reviews further confirmed the robustness of the interpretive findings and model, identifying congruence with evidence from health and other sectors, as highlighted in the discussion section below. Supplement 1 includes more details on considerations on the quality of the methods and analysis.

\section{How multisectoral collaboration works: country case study findings}

The multisectoral collaboration model (fig 1) synthesises findings across the case studies on what works in multisectoral collaboration.

In the model, "Drive change" includes a range of actors and factors that identify a need for, and initiate, a multisectoral collaboration. "Define," "design," and "realise" are deliberate, coordinated actions taken by sectors and stakeholders to tackle the identified need. Multisectoral collaboration is supported by the central component-"relate"-which includes the collaborative relationship as well as the integration of evidence, norms, and innovation in relation to all the different components. "Capture success" refers to how the collaborations define success and measure the results achieved. All six components in the model occur within a broader context of ongoing interactions and changing social and environmental contexts, and create a new force for collective action, learning, and change.

We elaborate on the six components of the multisectoral collaboration model, with higher level interpretive findings and illustrative country examples.

\section{Drive change}

All the multisectoral collaborations presented in this series sought to disrupt the status quo positively by instituting "business not as usual.” Across the case studies, drivers of change included a range of challenges or opportunities such as legislative, political, or socioeconomic changes, including the transition from low to middle income country status. In some cases, new data played a role by revealing a problem or gap; in others, scientific advances and innovation brought new possibilities for change. Media coverage and public attention often played an important part in instigating action, as did demands by stakeholders for harmonised policies and programmes to achieve common goals. In some countries, a high level "champion" was willing and able to kick start the collaboration and drive it forward.

Multisectoral collaboration being complex and requiring significant coordination and resources, stakeholders in all cases had to assess whether this was a better way to achieve the desired changes than reliance on action by an individual sector (box 2).

\section{Define}

Once a decision to engage in multisectoral collaboration was taken, the situation was strategically defined and framed so that all sectors and stakeholders could see their role and contribution to a common goal. Attention paid to defining the problem also influenced the type of solutions sought and the measures of success; "a problem well-put is half solved." ${ }^{20}$ In most cases the matter was framed in terms of overarching

\section{Box 2: Drive change: country examples}

Germany: For more than a decade, Germany has been making a concerted effort to ensure all children grow up healthy and safe.

Germany's Early Childhood Intervention programme supports nationwide goals of providing equal opportunities for all children to develop to their full potential. The programme includes cross sectoral collaboration as a central component, particularly between the social services sector and the health sector. Efforts contribute to nationwide support for cross sectoral networks supporting early childhood intervention, such as family midwifery and nursing services, and are part of a long term focus to ensure children grow up healthy and safe, particularly for families living in difficult circumstances.

A key driver of this programme is the rising share of children living in a family receiving social benefits, despite overall prosperity and strong economic growth in the country. Burdened families often slip through the social net and are driven towards susceptibility to harmful parental behaviour and in some cases, child maltreatment. High profile cases of child neglect in Germany led the public to demand for urgent action. ${ }^{26}$

Guatemala: After more than a decade of post-war reconstruction, inequities in the levels of maternal mortality between indigenous and nonindigenous women remained stark, indicating that the health system was not adequately meeting the needs of indigenous women.

One study found that a large portion of ethnic differences in the use of institutional delivery services between indigenous and non-indigenous women was attributable to indigenous women not speaking Spanish. This study and a 2015 health systems assessment for Guatemala indicated additional challenges with availability, accessibility, and quality of services for indigenous women.

In response, Indigenous Women's Organizations for Reproductive Health, Nutrition, and Education (ALIANMISAR) began working to tackle these problems, including the improvement of the quality and cultural acceptability of healthcare provided to indigenous women. As part of its mission, ALIANMISAR monitors a range of public health services at national, departmental, and municipal levels, in collaboration with other community based organisations, the executive and legislative sectors of the government (such as the Ministry of Health and the Ombudsman for Human Rights) and with international partners. To date, joint monitoring has contributed to important improvements in health policy and legislation, health services and infrastructure for indigenous women. ${ }^{27}$

India: India's immunisation programme is the largest in the world, with annual cohorts of around 26.7 million infants and 30 million pregnant women. Despite steady progress, routine childhood vaccination coverage has been slow to rise, with an estimated $38 \%$ of children failing to get all basic vaccines in the first year of life in 2016.

In response to low childhood vaccination coverage, India's Ministry of Health and Family Welfare launched Mission Indradhanush (MI) in 2014 and, based on the programme's success, the prime minister spearheaded an ambitious plan to accelerate progress further, launching Intensified Mission Indradhanush (IMI) in districts and urban cities with persistently low immunisation coverage with the aim of reaching $90 \%$ full coverage. IMI targeted areas with higher rates of unimmunised children and immunisation dropouts. A chain of support was established from the national level through states to districts, with senior staff providing regular reviews of progress and receiving updates on progress. ${ }^{28}$ 
Box 3: Define: country examples

Chile: A survey in 2005 found that $30 \%$ of Chilean children under the age of 5 were not reaching developmental milestones, with wide gaps between rich and poor.

Drawing on these survey results, Michelle Bachelet, a paediatrician and the first female president of Chile, set a goal to ensure optimal development for all children, regardless of background, origin, and socioeconomic status, by breaking the intergenerational cycle of poverty and reducing inequity.

The resulting initiative, Chile Grows with You (Chile Crece Contigo), is a comprehensive protection system for children from the prenatal period to 4 years, taking advantage of every encounter between children and health services, and providing coordinated services across different public sectors. ${ }^{29}$

Malaysia: The government of Malaysia approved funding for a multisectoral effort to support a human papillomavirus (HPV) immunisation programme for girls and significantly reduce the incidence of cervical cancer.

Prior to this, the cervical cancer screening programme had failed to achieve screening targets. There was increased political and public interest in the matter because of media stories about the illness and death from cancer of the prime minister's wife. There were also concerns that the vaccine could promote sexual promiscuity, be harmful to health, or not meet Islamic requirements.

Through a multisectoral effort, HPV immunisation was presented to stakeholders as a public good whose benefits outweighed its costs. Information from the telephone hotline, social media, and emails provided realistic and dynamic feedback on concerns about, and acceptance of, the vaccination programme. Key messages focused on cancer prevention and avoided sexual connotations, and the National Islamic Religious Authority issued a fatwa that the vaccine was permissible. ${ }^{30}$

South Africa: The South African government is increasingly concerned about the high rates of new HIV infections among adolescent girls and young women. It recognised that several social and structural factors underpinned this problem: poverty; unmet need for health and social services, including through educational institutions; gender inequality; and alcohol and substance abuse.

She Conquers, a three year national campaign launched by the government in June 2016, aimed to reduce the burden of HIV among women aged 15-24. The campaign moves beyond a focus on disease transmission and associated stigma to a narrative of power for adolescent girls and young women. Through multisectoral collaboration, the campaign expands a range of opportunities for adolescent girls and young women to claim their rights and decide their own futures. ${ }^{31}$

societal goals and values: for example, the human rights of indigenous communities, the agency and power of girls and women, and overcoming inequities in access to health and social services. In some countries the problem was further structured in more technical terms: for example, based on a specific health or sustainable development outcome, a service coverage gap, or the socioeconomic benefits of tackling a challenge (box 3).

\section{Design}

The solutions sought to the problems tackled by multisectoral collaboration were designed to build on existing structures, making innovations and adaptations for specific contexts. This process drew on diverse expertise from different sectors, and on feedback from stakeholders, to enhance relevance and impact. Although the design phase was often led by topic experts, the participation of stakeholders, including service users and the general public, was crucial. The feedback of service users in particular helped ensure the acceptability and perceived value of the designed solution.

Ensuring sufficient resources, for both the programme activities and the management of the multisectoral collaboration itself, was a critical concern. In some countries the coordination of multisectoral collaboration was funded from the outset.
Others started with seed funding. Across all the case studies, transitioning a project into an institutionalised programme with predictable (often government) funding was a desired objective. Designing mechanisms for regular, open communication among the multisectoral collaborators was also emphasised in many of the case studies (box 4).

\section{Realise}

Implementation involved both doing and learning, sometimes requiring openness to change course to achieve desired results Regular monitoring and evaluation enabled collaborations to redesign their approach when initial plans failed to achieve results, for example because programmatic barriers were not taken into account. Goals also evolved in response to unplanned effects and emerging political, health, and devel opment priorities or events. "Realise" is therefore a learning process, in which goals and strategies are continually tested and adjusted, rather than an undeviating linear process. ${ }^{21}$

An enabling factor for collaboration in this phase, particularly when scaling up, was finding the optimal balance between national level standardisation, support, and quality assurance on one hand, and the flexibility to adapt to local needs on the other. For example, national efforts for standardisation and capacity building can support local implementation. Successful local adaptations and initiatives can inform national guidance and support and be shared or scaled up across a country.

The "realise" component is an iterative process, often needing collaboration to redefine or redesign its planned action, or a component of it. This might be because of changes in the sectors or stakeholders involved, whether individuals or organisations. As the case studies show, these changes are sometimes planned, sometimes organic, sometimes initiated by an external or internal factor, and sometimes unanticipated (box 5).

\section{Relate}

Relationship building is central to all multisectoral collaborations. Investment in collaboration mechanisms enables open and regular communication, and facilitates the mutual understanding, trust, and accountability needed to achieve shared goals. Also important are mechanisms for all stakeholders to provide feedback throughout the process, to inform any adaptations needed.

Aligned with a collective logic of inquiry, ${ }^{20}$ multisectoral collaboration enabled diverse evidence and ideas to be tested, and encouraged innovation to tackle long standing constraints and achieve greater impact. Norms and 


\section{Box 4: Design: country examples}

Indonesia: A schools based iron supplementation project for adolescent girls in Indonesia provided a scalable model for anaemia reduction. The project focused on existing platforms and policy frameworks to catalyse multisectoral collaboration. Political commitment from policy makers within each sector drove the collaboration, as well as commitments from school administrators. Capacity building was needed at all levels, but investments in strengthening individual and institutional relationships across sectors helped foster collaboration. Harmonisation and collaboration on data collection, monitoring systems, as well as joint responsibility for, and ownership of, shared results, outcomes, and goals were key to engagement from all stakeholders. ${ }^{32}$

Malawi: Chipatala Cha Pa Foni (CCPF)-Chichewa for "health centre by phone"-is a free health and nutrition hotline. Launched in 2011 as a pilot project in one rural district of Malawi, it is now available nationwide to anyone with access to one of two major communications providers in Malawi. CCPF originally focused on pregnancy, antenatal, and postnatal advice, and advice for callers to seek facility care when appropriate. The programme has since expanded to include all standard health topics including water, sanitation, and hygiene; infectious diseases; and nutrition. Youth friendly services were introduced, increasing access to sexual and reproductive health information for young people. The service has the flexibility to handle emergent problems, such as cholera outbreaks. CCPF was developed iteratively by public, private, government, community, donor, and non-governmental stakeholders. CCPF will be one of the first government run nationwide health hotlines in Africa when the handover is completed in 2019. ${ }^{33}$

Sierra Leone: In May 2014, Sierra Leone reported its first Ebola case in Kailahun, a remote, marginalised, and impoverished district bordering Liberia. The district experienced one of the highest concentrations of Ebola infections during this outbreak, during which over 1600 children were orphaned and gender inequalities were exacerbated. Public health control measures put in place by the Sierra Leonean government included closing all schools, and prohibiting public congregation. While many other educational services ceased operations entirely in Kailahun, the partners involved in Getting Ready for School redesigned the project into a radio education programme called Pikin to Pikin Tok (PtPT), meaning Child to Child Talk in Krio. Over 30 children affected by the Ebola crisis, who had been young facilitators in the original programme, worked alongside PtPT's field staff to develop the radio programmes, conduct interviews, make recordings for the radio programmes, and ensure the project remained child centred. Children involved in the programme became empowered, gaining experience as journalists and facilitators, and encouraged by listener groups to challenge adults, including parents and government representatives. They critically assessed their circumstances and how to support and protect each other, and openly discussed subjects normally regarded as taboo or difficult, such as sexual abuse. $^{34}$

values were interlinked with evidence as an explicit consideration in the case studies, particularly in terms of respecting positive sociocultural norms, shifting away from harmful norms, or developing and formalising new norms, for example, through standards, guidance, or official agreements.

Multisectoral collaboration is a dynamic process that occurs within wider interactions and networks and changing political, social, and environmental contexts (figure 1). Different stakeholders were more or less strongly engaged at different stages in the collaboration, depending on their roles, which were defined more or less formally. In some cases, a cross cutting coordination

\section{Box 5: Realise: country examples}

Afghanistan: Decades of war and instability had left most people without access to primary health services. In response, Afghanistan's Basic Package of Health Services (BPHS) was introduced in 2003 at the primary care level and is an example of an innovative multisectoral collaboration implementing, scaling, and iteratively refining health service delivery in a poor, post-conflict crisis setting.

Afghanistan's distinctive BPHS was rolled out nationwide and the delivery of BPHS services in 31 of Afghanistan's 34 provinces was the responsibility of NGOs-through a contracting-out mechanism. The entire development of the BPHS reflected the multisectoral collaboration in its design, execution, and oversight. The programme was stewarded and implemented by the Ministry of Public Health with contributions from numerous ministries and is an example of how various stakeholders and sectors collaborate to implement a basic health structure. ${ }^{35}$

Cambodia: IDPoor is a step in Cambodia's ongoing evolution towards a comprehensive social protection system and promoting equity. IDPoor's origin is linked to the health sector and the introduction of the national Health Equity Fund to reduce financial barriers in access to healthcare. With assistance from development partners, the Ministry of Planning formulated a national, cross sectoral poverty identification mechanism to establish an integrated social registry to serve multiple social assistance programmes. The Ministry of Planning assumed an essential coordinating and administrative function, which was qualitatively different from the functions of technical line ministries that oversee service delivery. This cross cutting coordination function was essential to engage with a variety of sectors and stakeholders. Active involvement of relevant ministries at national and sub-national level, communal structures, NGOs, and development partners helped to build a consensus on the national guidelines and contributed to wide acceptance and use of IDPoor. ${ }^{36}$

USA: The Voices for Healthy Kids initiative launched in February 2013 as a multisectoral, multistakeholder collaboration co-created by the American Heart Association and the Robert Wood Johnson Foundation. The initiative engages, organises, and mobilises advocates to improve health in their communities by helping all children and adolescents achieve a healthy weight. This strategy is based on the premise that policy and environmental changes to improve food and physical activity settings are vital to support and enable people's healthy weight efforts, and can also promote public health. The initiative aims to build capacity in state and local coalitions by awarding grant funding to advocates of policy changes that make healthy foods and beverages and physical activity more accessible and affordable where children and adolescents live, learn, grow, and play. Voices for Healthy Kids now convenes and coordinates more than 140 stakeholder organisations from the arenas of social justice, physical activity, nutrition, education, transportation, food access, school health, and other sectors to advance policy changes. ${ }^{37}$ 
Table 2 | Illustrative examples of a spectrum of successes in the country case studies

Success characteristics Selected examples

Contribution to health and Sustainable Health related results, including for equity, gender, and human rights:

Development Goals

- Around six million children were vaccinated within a three month period, with over 850000 children vaccinated for the first

time. Children fully vaccinated by 12 months of age rose by around $18.5 \%$ in IMI target districts to $69 \%$ coverage (India) ${ }^{28}$

- Changes in the attitudes of health providers to the provision and access of culturally appropriate and high quality services for women from indigenous communities (Guatemala) ${ }^{2}$

Multisectoral related results, including for equity, gender, and human rights:

- Among the three million adolescent girls and young women aged 15-24 years in 22 priority sub-districts, more than 72000 got support to remain in school, and to gain access to health and other social services (South Africa) (31 $^{3}$

- Around 2.2 million people living in poverty ( $25 \%$ of them women of reproductive age and $30 \%$ children under 15 ) received an equity card from the governments' nationwide poverty targeting system, IDPoor, giving them access to free healthcare and other services (Cambodia) ) $^{36}$

Collaborative relationships, innovation, Collaboration management and mechanisms:

and incentives

- The non-sectoral Ministry for Social Development, experienced in managing social networks and promoting social development policies, promotes better coordination of multisectoral activities, rather than focusing on the activities of one sector (such as health or education). Coordination takes place across ministries and services at the same level (horizontal coordination) and across different levels of government from national to commune level (vertical coordination) (Chile ${ }^{29}$

- The decades old culture of collaboration between the health and education sectors gained new impetus through the opportunity for providing HPV immunisation to schoolgirls; new collaborations between public and private sectors emerged in response to resource constraints and a national emphasis on multisectoral collaboration (Malaysia) ${ }^{30}$

Resources for programmes and for the collaborations:

- Programmes in fragile settings were sustained by committed donor funding. Donors who were hesitant about providing direct funding chose trust funds as a more secure means of contributing, because of higher transparency and mutual accountability associated with this mechanism (Afghanistan) ${ }^{3}$

- With robust evidence of its positive impact, the Federal Foundation for Early Childhood Intervention became a mandatory federal programme at the beginning of 2018 , receiving approximately $€ 51 \mathrm{~m}(£ 44 \mathrm{~m} ; \$ 59 \mathrm{~m})$ per year (Germany) ${ }^{26}$

Research, monitoring, and evaluation:

- Innovative measurement and evaluation processes were developed, to which all stakeholders contributed. An example is the concept of "policy wins," defined as the enactment of legislation, regulations, executive orders, or ballot measures, which Voices for Healthy Kids championed at state or local level. Over 140 policy wins were achieved, including to improve the availability of healthy food and opportunities for safe physical activity, and to reduce inequalities in social justice, education, transportation, food access, school health, and other sectors. Early and continuous investment in monitoring and evaluating a wide spectrum of results helped to drive continuous improvement and comprehensive change (USA) ${ }^{37}$

- In the national Anaemia Prevention and Control Programme in Adolescent Girls and Women of Reproductive Age (WIFAS policy) data drove decisions and accountability. Sectors harmonised data collection and monitoring systems, with joint responsibility for, and ownership of, results; this was key to building trust and strengthening the engagement of all stakeholders (Indonesia) 32 $^{2}$

Scale and sustainability

- Access to education was maintained during the Ebola outbreak through child led radio broadcasts reaching over 500000 people. Community awareness of the value of education, especially for girls, increased. The programme also acted as a catalyst for new programmes: Child to Child and Pikin-to-Pikin, in collaboration with Romeo Dallaire Child Soldiers Initiative and former child soldiers, are developing a further programme of radio broadcasts (Sierra Leone) ${ }^{34}$

- Adherence to Ministry of Health guidelines and protocols was strengthened through training documentation, nutrition guidelines, and disease surveillance, for example. Transitioned from a local innovation serving one district to national scale, supporting 60000 Malawians from all 28 districts. Ownership is transitioning from NGO to government (Malawi) ${ }^{33}$

function-through, for example, ministries of planning or finance-was helpful to connect specific technical sectors and engage a wide range of stakeholders.

A shared sense of identity in multisectoral collaboration often developed in response to a specific context, including the ability to learn, adapt, and evolve in response to ongoing developments on the ground. Global and regional stakeholders' contributions were also valued, especially in times of crisis and to tackle shortfalls in technical capacity or resources.

\section{Capture success}

The collaborations defined their successes across a spectrum of results (table 2). The country case studies were explicitly selected on the basis of their having described, in responding to the call for proposals, some degree of success relating broadly to health and sustainable development outcomes. The call did not predefine success but left this for applicants to describe. The diversity of interpretations, as manifested in the broad spectrum of successes reported, is a key finding in itself. It indicates that different paradigms and definitions of success are at play here, and that "there is no one truth" about what constitutes success in multisectoral collaboration. ${ }^{2138}$

Nevertheless, across the case studies, three common components of success are evident: a contribution to health and sustainable development goals, including benefits perceived by service users; success within the collaboration in terms of strength of relationships, innovation, and incentives; and the scaling up and sustainability of the effort. These components highlight a common view that multisectoral action is valuable for both the means and the ends achieved.

The positive results reported by the case studies, however, need to be considered with caution. Two critical caveats are the self defined nature of the successes and the extent to which they are directly attributable to multisectoral collaboration (as a standard intervention), given the diversity of contexts and collaborations. For example, the studies did not involve comparison with populations who were not exposed to multisectoral collaboration, and few had pre-post measures. Nonetheless, based on evidence of improvements in processes and intermediary outcomes, ${ }^{17} 38$ plausible assumptions can be made about the potential positive contribution made by the collaborations to health and sustainable development outcomes.

Capturing success also requires learning from failure and adaptation to challenges and change. In some cases, collaborative relationships took longer to establish because the problem was not framed in a way that all sectors and stakeholders could see the benefits of working together. This 
often required several iterations. The lack of engagement of key stakeholders and experts in relevant programme components reduced the ability to coordinate action and to adapt-for instance to tailor services appropriately for high risk groups and local circumstances. It also led to delays in the transition to scaling up or government ownership of programmes.

The multisectoral collaborations faced a range of ongoing or new challenges which required adaptive and innovative responses, as highlighted in "realise." Adaptive strategies included raising additional funds to meet financial shortfalls; collaborating with media to increase public awareness of, and support for, the programme; strengthening systems to support multisectoral services; and regularly monitoring and responding constructively to changing political, demographic, and social changes, including emergency situations.

\section{Discussion}

Despite the case studies being heterogeneous in terms of their geographic, economic, social, cultural, and historical contexts, strong similarities were identified in how multisectoral collaborations were initiated, managed, and taken to scale (figure 1). These higher level findings and shared lessons allow governments and other implementers to showcase their achievements and learn from real world experiences of how multisectoral collaboration works.

The findings in this paper reflect and supplement those in the literature on multisectoral collaboration, including in the areas of education, nutrition, non-communicable diseases, and early childhood development. ${ }^{12152339}$ Our findings highlight the need to build on local resources and structures, embed quality assurance mechanisms within implementation, and ensure relevance and adaptability to context, based on service users' experiences and perspectives. The importance of building a shared understanding of diverse stakeholder interests and contributions, investing in ongoing and open communication, and managing stakeholder relations is also evident. ${ }^{812222340}$ Finally, the need for continued commitment when pursuing coordinated action is emphasised, with the flexibility to learn from results and to make required changes along the way. ${ }^{4142}$

We provide new insights into the dynamics and effects of multisectoral collaboration. Multisectoral collaboration is not a constant configuration, ${ }^{23}$ but a dynamic and evolving process, during which stakeholders and their engagement may change across different components and contexts of the collaboration. The collaborations were intentional new modes of collective action that generated new learning and new ways of working as they evolved, to achieve transformative results. Stakeholders strategically framed a challenge or opportunity that all sectors could relate to and explicitly deliberated on the evidence, norms, and innovation needed to shape all components of the collaboration.

Collaboration across the case studies show three common elements of success: contribution to health and sustainable development goals; collaborative relationships, innovation, and incentives; and scaling up and sustainability of the effort. More studies are needed to further define success for multisectoral collaborations and strengthen measurement.

The case studies' findings offer plausible associations for the positive results of multisectoral collaboration. These should, however, be interpreted with caution given the limitations in measurement, comparability, and attribution, especially with regards to health and development outcomes. There are challenges in demonstrating and attributing direct impacts of multisectoral collaboration as an intervention. Research and evaluation in this area is needed, however, to develop and test hypotheses about the specific factors that contribute to success, which would also inform investment and practice in this area.

Important areas for further work include the development and standardisation of indicators-such as on the perceived value of collaborative relationships and incentives, or on scaling up and sustainability. The case studies here focus on success stories: future efforts could focus on developing a systematic way to analyse failed collaborations and the lessons to be learned from them.

Specific methods and tools (box 6) could help to apply in practice the six components of the model presented here, and facilitate testing and further development.

\section{Conclusion}

This article and the country case studies offer fresh insight into how diverse sectors can intentionally shape new ways of collaborating and learning in order to transform situations and achieve shared goals. The strategies described above contributed to incentives for the sectors involved, and for the public good. The multisectoral collaboration model which has emerged from this paper is relevant for other partnerships and collaborative efforts seeking to work together better and achieve positive transformative change.

The authors thank all of the broader PMNCH Multisectoral Collaboration Study Group comprising the country teams and stakeholders who contributed to the development of the case studies within this Series, and on which this synthesis paper is based Many colleagues contributed to the development of the methods and selection of the case studies, including Laura Frost, Beatrice Halpaap, Beth Ann Pratt, expert reviewers of eligible proposals received from the call for proposals, the United Nations H6 Working Group, and members of the PMNCH Secretariat. The authors also appreciate contributions

Box 6: Examples of tools and methods to support the application of the multisectoral collaboration model

The multisectoral collaboration model is based on the "logic of inquiry" as an overarching method. ${ }^{20}$ In addition, there are specific methods and tools to help operationalise the six components of the model.

1 Drive change: set agendas and mobilise a critical mass of stakeholders for change, ${ }^{41}$ ascertain whether the situation is best tackled by multisectoral collaboration, and optimise linkages across sectors and SDGs ${ }^{573}$

2 Define: clarify the situation in a way that improves how problems are assessed, and enables stakeholders to agree on a course of action and develop a well defined project ${ }^{44}$

3 Design: build on existing mechanisms and sectoral expertise to plan programmes, set up governance for the multisectoral collaboration, and develop innovations that are relevant to stakeholders, contexts, and goals ${ }^{81245}$

4 Realise: strengthen implementation, monitoring, and evaluation as iterative and adaptive processes that facilitate learning from successes and failures, and adapt to change ${ }^{45}$

5 Relate: systematically assess and strengthen synergies between sectors, ${ }^{5743}$ manage multisectoral collaborations, ${ }^{812}$ and promote multistakeholder dialogue and deliberation ${ }^{46}$

6 Capture success: use a range of qualitative and quantitative methods to monitor and evaluate results comprehensively and promote learning from both successes and failures, ${ }^{1738}$ and formulate multisectoral collaboration as an intervention to which health and development outcomes can be attributed. ${ }^{47}$ 
by colleagues who reviewed and provided advice on the paper, including PC Abraham, Philipp Dorstewitz, Nicholas Furtado, Anna Rayne, and John Reeder. The paper greatly benefited from the BMJ peer reviewers, Karen Daniels, Evelyne de Leeuw, and Purnima Menon, who provided valuable direction to finalise the paper and highlighted related findings across sectors, and the BMJ editors, Paul Simpson and Emma Veitch whose guidance throughout the process was invaluable.

Contributors and sources: SK and WG as co-chairs of the global steering committee, together with $\mathrm{RH}$ the project coordinator, and inputs from all authors, conceptualised and coordinated the development of the multisectoral collaboration case studies and synthesis paper. SK, RH, WG, JMM, JFV, RB, and DH conducted the synthesis of case study findings. Other global steering committee members (TB, NC, RC, PF, SP, KR, JR, KLS, PT, YV, MNW, listed alphabetically on the byline), and lead authors and consultants on the 12 country case studies (CEA, SB, CB, SNB, LB, EAC JD, VG, MWK, HMM, JM, IR, MLR, VS, SS, HS, DU, CNV, PY, also alphabetical on byline) reviewed the findings and contributed to all drafts of the paper, including by writing sections. PMNCH provided funding to support the country case study teams, including to convene multistakeholder dialogues and for consultancy support as required. All other authors, across a range of organisations and as members of PMNCH, contributed their time and inputs to the study processes and journal article. Shyama Kuruvilla is the guarantor of the article on behalf of the PMNCH Multisectoral Collaboration Study Group.

Competing interests: We have read and understood BMJ policy on declaration of interests and have the following interests to declare: $\mathrm{RH}$ is employed by PMNCH, which provided funding to support the country case study teams; CEA, SB, CB, SNB, LB, EAC, JKD, JFV, VG, HMM, JM, JM, IR, MLR, VS, SS, HS, DU, CNW, PY received funding from PMNCH for consultancy fees and related costs for undertaking the case study. All other authors contributed in kind to this collective effort with their time and inputs.

Provenance and peer review: Commissioned, externally peer reviewed.

This article is part of a series proposed by the Partnership for Maternal, Newborn, and Child Health and commissioned by The BMJ, which peer reviewed, edited, and made the decision to publish the article. Open access fees for the series are funded by PMNCH.

Shyama Kuruvilla, senior strategic adviser ${ }^{1}$

Rachael Hinton, technical officer ${ }^{2}$

Ties Boerma, director and professor ${ }^{3}$

Ryan Bunney, intern

Nuria Casamitjana, training and education director ${ }^{5}$

Rafael Cortez, senior economist and team lead ${ }^{6}$

Patrizia Fracassi, senior nutrition analyst and strategy adviser

Jennifer Franz-Vasdeki, independent consultant ${ }^{8}$

Daniel Helldén, research assistant ${ }^{9}$

Joanne McManus, independent consultant ${ }^{10}$

Susan Papp, managing director of policy and advocacy ${ }^{11}$

Kumanan Rasanathan, coordinator health systems ${ }^{12}$ Jennifer Requejo, senior adviser ${ }^{13}$

Karlee L Silver, co-chief executive officer ${ }^{14}$

Petra Tenhoope-Bender, technical adviser ${ }^{15}$

Yael Velleman, senior policy analyst ${ }^{16}$

Mary Nell Wegner, executive director ${ }^{17}$

Corinne E Armstrong, independent consultant ${ }^{18}$

Sarah Barnett, counsultant ${ }^{19}$
Carla Blauvelt, country director ${ }^{20}$

Saidatul Norbaya Buang, public health physician ${ }^{2}$

Louise Bury, independent consultant ${ }^{22}$

Emily A Callahan, consultant ${ }^{23}$

Jai K Das, senior instructor ${ }^{24}$

Vandana Gurnani, joint secretary ${ }^{25}$

Mary White Kaba, independent consultant ${ }^{26}$

Helia Molina Milman, dean of the medical sciences faculty ${ }^{27}$

John Murray, independent consultant ${ }^{28}$

Ilona Renner, research manager ${ }^{29}$

Marion Leslie Roche, senior technical adviser ${ }^{30}$

Victoria Saint, independent consultant ${ }^{31}$

Sarah Simpson, independent consultant ${ }^{32}$

Hasina Subedar, adviser ${ }^{33}$

Daria Ukhova, independent consultant ${ }^{34}$

Claudia Nieves Velásquez, independent consultant ${ }^{35}$

Patricia Young, director ${ }^{36}$

Wendy Graham, professor ${ }^{37}$

${ }^{1}$ World Health Organization, Geneva, Switzerland

${ }^{2}$ Partnership for Maternal, Newborn, and Child Health, Geneva, Switzerland

${ }^{3}$ Countdown to 2030, and University of Manitoba, Manitoba, Canada

${ }^{4}$ World Health Organization, Chicago, USA

${ }^{5}$ ISGlobal, Barcelona Institute for Global Health, University of Barcelona, Spain

${ }^{6}$ World Bank, Washington DC, USA

${ }^{7}$ Scaling up Nutrition Secretariat, Geneva, Switzerland

${ }^{8}$ Seattle, USA

${ }^{9}$ Department of Public Health Sciences, Karolinska Institutet, Stockholm, Sweden

${ }^{10}$ Oxford, UK

${ }^{11}$ Women Deliver, New York, USA

${ }^{12}$ WHO Cambodia, Phnom Penh, Cambodia

${ }^{13}$ UNICEF, New York, USA

${ }^{14}$ Grand Challenges Canada, Toronto, Canada

${ }^{15}$ UNFPA, Geneva, Switzerland

${ }^{16}$ WaterAid, London, UK

${ }^{17}$ Maternal Health Task Force, Harvard University TH Chan School of Public Health, Boston, Massachusetts, USA

${ }^{18}$ London, UK

${ }^{19}$ SB Consultancy World, Bristol, UK

${ }^{20}$ VillageReach, Lilongwe, Malawi

${ }^{21}$ Family Health Development Division, Ministry of

Health, Kuala Lumpur, Malaysia

${ }^{22}$ Global Research Consultancy, Ipswich, UK

${ }^{23}$ EAC Health and Nutrition, Washington DC, USA

${ }^{24}$ Division of Women and Child Health, Aga Khan University, Karachi, Pakistan

${ }^{25}$ Ministry of Health and Family Welfare, Government of India, New Delhi, India

${ }^{26}$ Montreal, Canada

${ }^{27}$ University of Santiago, Chile

${ }^{28}$ Iowa City, Iowa, USA

${ }^{29}$ National Centre for Early Prevention, Federal Centre for Health Education, Cologne, Germany

${ }^{30}$ Nutrition International, Adolescents' and Women's

Health and Nutrition, Ottawa, Ontario, Canada

${ }^{31}$ Berlin, Germany, Council on International

Educational Exchange (CIEE), Berlin, Germany

${ }^{32}$ EquiAct 71, Montluel, France

${ }^{33}$ National Department of Health, Pretoria, South Africa
${ }^{34}$ Berlin, Germany

${ }^{35}$ Guatemala City, Guatemala

${ }^{36}$ Child to Child, London, UK

${ }^{37}$ London School of Hygiene and Tropical Medicine, London, UK

Correspondence to: S Kuruvilla

kuruvillas@who.int

\section{(c) (1) (8) \\ OPEN ACCESS}

This is an Open Access article distributed under the terms of the Creative Commons Attribution IGO License (https://creativecommons.org/licenses/bync/3.0/igo/), which permits use, distribution, and reproduction for non-commercial purposes in any medium, provided the original work is properly cited.

\section{D) Check for updates}

1 United Nations General Assembly. Transforming our world: the 2030 agenda for sustainable development. United Nations, 2015. www.un.org/ga/ search/view_doc.asp?symbol=A/RES/70/1\&Lang=E.

2 Every Woman Every Child. Global strategy for women's, children's and adolescents' health (2016-2030). 2015. www.everywomaneverychild. org/global-strategy.

3 World Health Organization. Together on the road to universal health coverage: a call to action. 2017. http://apps.who.int/iris/bitstream/ handle/10665/258962/WHO-HIS-HGF-17.1-eng. pdf? sequence $=1$.

4 World Health Organization. Time to deliver: report of the WHO Independent High-Leve Commission on Noncommunicable Diseases. 2018. http://apps.who.int/iris/bitstream/han dle/10665/272710/9789241514163-eng pdf?ua $=1$.

5 World Health Organization. Health in all policies: training manual. 2015. www.who.int/social_ determinants/publications/health-policiesmanual/en.

6 Brugha R, Varvasovszky Z. Stakeholder analysis: a review. Health Policy Plan 2000;15:239-46. doi:10.1093/heapol/15.3.239

7 World Business Council for Sustainable Development SDG sector roadmaps: how to leverage the power of sectoral collaboration to maximize business impac on the Sustainable Development Goals. 2018. http://docs.wbcsd.org/2018/04/SDG_roadmap\%20 Guidelines.pdf.

8 Rasanathan K, Bennett S, Atkins V, et al. Governing multisectoral action for health in low- and middle-income countries. PLOS Med 2017;14:e1002285. doi:10.1371/journal. pmed.1002285

9 Tangcharoensathien V, Srisookwatana O, Pinprateep P, Posayanonda T, Patcharanarumol W. Multisectoral actions for health: challenges and opportunities in complex policy environments. Int J Health Policy Manag 2017;6:359-63. doi:10.15171/ijhpm.2017.61

10 Wang H, Liddell CA, Coates MM, et al. Global, regional, and national levels of neonatal, infant, and under-5 mortality during 1990-2013: a systematic analysis for the Global Burden of Disease Study 2013. Lancet 2014;384:957-79. doi:10.1016/S0140-6736(14)60497-9

11 Partnership for Maternal, Newborn, and Child Health, World Health Organization, World Bank, Alliance for Health Policy and Systems Research. Success factors for women's and children's health study series: journal articles and country reports. World Health Organization, 2015. www.who.int/pmnch/ successfactors/en. 
12 de Leeuw E. Engagement of sectors other than health in integrated health governance, policy, and action. Annu Rev Public Health 2017;38:329-49. doi:10.1146/annurev-publhealth-031816-044309

13 Levinson J, Balarajan Y. Addressing malnutrition multisectorally: what have we learned from recent international experience? Unicef, 2013.

14 Global Health Insights. Case study development based on a review of the evidence: collaborating across sectors for women's, children's, and adolescents' health. 2017. www.who.int/pmnch/ knowledge/working-report-case-study-development. pdf.

15 Neuman MJ, Devercelli AE. What matters most for early childhood development? A framework paper. Systems Approach for Better Education Results (SABER) working paper series. World Bank Group, 2013.

16 Every Woman Every Child. EWEC partners' framework for 2018-2020. https://drive.google.com/file/ d/OB6F0e_DigW1aZUVpT1hoMmpmcUU/view.

17 Mays N, Pope C, Popay J. Systematically reviewing qualitative and quantitative evidence to inform management and policy-making in the health field. I Health Serv Res Policy 2005:10(Suppl 1):6-20. doi:10.1258/1355819054308576

18 Goldkuhl G, Cronholm S. Adding theoretical grounding to grounded theory: Toward multigrounded theory. Int / Qual Methods 2010;9:187205doi:10.1177/160940691000900205.

19 Partnership for Maternal, Newborn and Child Health. Methods guide for country case studies on successful collaboration across sectors for health and sustainable development. World Health Organization, 2018. www.who.int/pmnch/knowledge/case-studymethods-guide.pdf.

20 Arora M, Chauhan K, John S, Mukhopadhyay A. Multi-sectoral action for addressing social determinants of noncommunicable diseases and mainstreaming health promotion in national health programmes in India. Indian I Community Med 2011;36(Suppl 1):S43-9. doi:10.4103/0970-0218.94708

21 Garrett J, Natalicchio M, Bassett L. Working multisectorally in nutrition: Principles, practices, and case studies. International Food Policy Research Institute, 2011.

22 Dewey J. Logic: the theory of inquiry. In: Boydston JA, Hickman LA, eds. The Collected Works of John Dewey, 1882-1953. Carbondale and Edwardsville: Southern Illinois University Press

23 Kuruvilla S, Dorstewitz P. There is no "point" in decision-making: a model of transactive rationality for public policy and administration. Policy Sci 2010;43:263-87doi:10.1007/s11077-0099098-y.

24 Edenhofer O, Kowarsch M. Cartography of pathways: A new model for environmental policy assessments. Environ Sci Policy 2015;51:56-64doi:10.1016/j. envsci.2015.03.017.
25 Ansell C, Boin A. Taming deep uncertainty: The potential of pragmatist principles for understanding and improving strategic crisis management. Adm Soc 2017. doi:10.1177/0095399717747655.

26 Renner I, Saint V, Neumann A, et al. Improving psychosocial services for vulnerable families with young children: strengthening links between health and social services in Germany. BM/ 2018:363:k4786. doi:10.1136/bmj.k4786

27 Velásquez CN, del Rosaria Garcia Meza M, Ukhova D, et al. Making the health system work by and for indigenous women in Guatemala: a community-led multisectoral collaboration. BMJ 2018;363:k4677. doi:10.1136/bmj.k4677

28 Gurnani V, Haldar P, Aggarwal MK, et al. Improving vaccination coverage in India: lessons from Intensified Mission Indradhanush, a crosssectoral systems strengthening strategy. BMJ 2018;363:k4782. doi:10.1136/bmj.k4782

29 Molina MH, Castillo CA, Torres Sansotta A, et al. Scaling up an early childhood development programme through a national multisectoral approach to social protection: lessons from Chile Crece Contigo. BMJ 2018;363:k4585.

30 Buang SN, Ja'afar S, Pathmanathan I, et al. Human papilloma virus immunisation of a dolescent girls: improving coverage through multisectoral collaboration in Malaysia. BMJ 2018;363:k4602

31 Subedar H, Barnett S, Chaka T, et al. Tackling HIV by empowering adolescent girls and young women: a multisectoral government-led campaign in South Africa. BMJ 2018;363:k4585.doi:10.1136/bmj. k4585.

32 Roche ML, Bury L, Novitasari Yusadiredjai I, et al. Adolescent girls' nutrition and prevention of anaemia: a school-based multisectoral collaboration in Indonesia. BMJ 2018;363:k4541.doi:10.1136/ bmj.k4541.

33 Blauvelt C, West M, Maxim L, et al. Scaling up a health and nutrition hotline in Malawi: the benefits of multisectoral collaboration. BM/ 2018:363:k4590. doi:10.1136/bmj.k4590

34 Barnett S, van Dijk J, Swaray A, et al. Redesigning an education project to child friendly radio: a multisectoral collaboration to promote children's health, education, and human rights after humanitarian crisis in Sierra Leone. BMJ 2018;363:k4667.doi:10.1136/bmj.k4667

35 Das JK, Akseer N, Mirzazada S, et al. Scaling up primary health services for improving reproductive, maternal and child health: a multisectoral collaboration in a conflict setting of Afghanistan. BMJ 2018;363:k.4986. doi:10.1136/bmj.k4986

36 White Kaba M, Baesel K, Poch B et al. "IDPoor": enabling collaboration across sectors for maternal and child health in Cambodia through a poverty identification programme. BMJ 2018;363:k4698. doi:10.1136/bmj.k4698
37 Callahan E, Hollander M, Vaca McGhie D, et al. Voices for Healthy Kids: a multisectoral collaboration to accelerate policy changes that promote healthy weight for all children and adolescents in the United States. BM/ 2018:363.k4763 doi:10.1136/bmj.k4763.

38 Patton MQ. Qualitative research and evaluation methods. 4th ed. Sage Publications Inc, 2015.

39 Bay JL, Morton SM, Vickers MH. Realizing the potential of adolescence to prevent transgenerational conditioning of noncommunicable disease risk: Multisectoral design frameworks. Healthcare (Basel) 2016;4:39. doi:10.3390/ healthcare 4030039

40 Brouwer H, Hiemstra W, Vugt S, Walters H. Analysing stakeholder power dynamics in multi-stakeholder processes: insights of practice from Africa and Asia. Knowl Manag Dev J 2013;9:11-31.

41 Shiffman I. Generating political priority for maternal mortality reduction in 5 developing countries. Am J Public Health 2007;97:796-803. doi:10.2105/ AJPH.2006.095455

42 Webb K, Hawe P, Noort M. Collaborative intersectoral approaches to nutrition in a community on the urban fringe. Health Educ Behav 2001;28:306-19. doi:10.1177/109019810102800305

43 Blomstedt Y, Bhutta ZA, Dahlstrand J, et al. Partnerships for child health: capitalising on links between the sustainable development goals. BMI 2018.360.k125. doi:10.1136/bmik125

44 Rosenhead J, Mingers J. Rational analysis for a problematic world revisited: problem structuring methods for complexity, uncertainty, and conflict. 2nd ed. John Wiley \& Sons, 2001

45 H6 agencies-UNAIDS, UNFPA, Unicef, UN Women, World Bank Group, WHO. Implementation toolkit in support of the Global Strategy for Women's, Children's and Adolescents' Health. Every Woman Every Child. 2016. www.everywomaneverychild.org/ h6-toolkit.

46 PMNCH. WHO, CM Partners, et al. Multistakeholder dialogues for women's and children's health: A guide for conveners and facilitators. WHO, 2014.

47 Mays G. Research findings: delivery and financing systems for health care and public health services. https://health.maryland.gov/healthenterprisezones/ Documents/Research\%20on\%20Delivery\%20 and $\% 2$ Financing $\% 20$ System $\% 20$ for $\% 20$ Health\%20Care\%20and\%20Public\%2OHealth\%20 Services \%20Glen\%20P\%20Mays\%20PhD \%20 MPH.pdf.

Supplement 1: Developing a multisectoral collaboration model: a methods roadmap

See www.bmj.com/multisectoral-collaboration for other articles in the series.

Cite this as: $B M / 2018 ; 363: k 4771$

http://dx.doi.org/10.1136/bmj.k4771 